\title{
Investigation of structural, optical and electrical properties of (Ti,Nb)Ox thin films deposited by high energy reactive magnetron sputtering
}

\author{
Michal Mazur*, Danuta Kaczmarek, Eugeniusz Prociow, Jaroslaw Domaradzki, \\ DAMIAN WOJCIESZAK, JAKUB BOCHEŃSKI
}

Faculty of Microsystem Electronics and Photonics, Wroclaw University of Technology, Janiszewskiego 11/17, 50-372 Wroclaw

\begin{abstract}
In this work the results of investigations of the titanium-niobium oxides thin films have been reported. The thin films were manufactured with the aid of a modified reactive magnetron sputtering process. The aim of the research was the analysis of structural, optical and electrical properties of the deposited thin films. Additionally, the influence of post-process annealing on the properties of studied coatings has been presented. The as-deposited coatings were amorphous, while annealing at $873 \mathrm{~K}$ caused a structural change to the mixture of $\mathrm{TiO}_{2}$ anatase-rutile phases. The prepared thin films exhibited good transparency with transmission level of ca. $50 \%$ and low resistivity varying from $2 \Omega \mathrm{cm}$ to $5 \cdot 10^{-2} \Omega \mathrm{cm}$, depending on the time and temperature of annealing. What is worth to emphasize, the sign of Seebeck coefficient changed after the annealing process from the electron to hole type electrical conduction.
\end{abstract}

Keywords: (Ti,Nb)Ox thin films; transparent oxide semiconductor; p-type electrical conduction; niobium doped titanium dioxide; transparent electronics

(C) Wroclaw University of Technology.

\section{Introduction}

In the recent years a growing interests in research concerning modification of electrical properties of $\mathrm{TiO}_{2}$ has been observed [1-6]. Nowadays, due to addition of dopants into the $\mathrm{TiO}_{2}$ it is possible to prepare coatings, which at room temperature are conducting (TCO - Transparent Conducting Oxides) or semiconducting (TOS - Transparent Oxides Semiconductors) thin films. Such transparent and electrically conducting or semiconducting coatings can find wide application, for example, in new dynamically developed field of science, which relates to electronics and photonics, so-called Transparent Electronics. A distinct increase of interests in oxides has been observed, especially for those, which are high-temperature stable, chemically resistant, easy applicable to a largescale production and abundant.

\footnotetext{
*E-mail: michal.mazur@pwr.wroc.pl
}

One of the first reports on transparent conducting oxides of $\mathrm{TiO}_{2}$ : $\mathrm{Nb}$ thin films has been published by Furubayashi et al. [4]. TCO thin films with similar properties have also been reported by other authors while using such dopants as tantalum or ruthenium. $\mathrm{TiO}_{2}$ doped with $\mathrm{Nb}$, Ta or $\mathrm{Ru}$ usually exhibits electron type conduction. However, in the work [6] the authors have also shown that doping of $\mathrm{TiO}_{2}$ with cobalt enabled the creation of semiconducting films with the hole type conductivity. Unfortunately, such well conductive and welltransparent thin films were obtained only after additional annealing of the prepared structures at a temperature of at least $300{ }^{\circ} \mathrm{C}$ in hydrogen, nitrogen or in a vacuum $[4,5,9,10]$. As a result, their application, for example as a transparent electrode in already existing devices, such as silicon devices, is limited.

In this work, the results of investigations of the structural, optical and electrical properties of thin films of titanium-niobium oxides, denoted here as 
( $\mathrm{Ti}, \mathrm{Nb}) \mathrm{Ox}$, prepared by the high energy reactive magnetron sputtering method have been outlined.

\section{Experiment}

The $(\mathrm{Ti}, \mathrm{Nb}) \mathrm{Ox}$ thin films were prepared by the high energy reactive magnetron sputtering (HE RMS) method [11] using Ti-Nb mosaic target. The sputtering process was carried out at a low pressure $(0.1 \mathrm{~Pa})$, in reactive atmosphere using high purity oxygen $(99.99 \%)$ as a working and reactive gas. The low pressure of the sputtering allowed us to obtain a longer mean free path, which enabled oxygen ions to bombard the target surface with higher energy [12]. As a result the deposition rate and ion flux decreased. The sputtering power during the deposition process was equal to ca. $1.15 \mathrm{~kW}$. The circular magnetron, $100 \mathrm{~mm}$ in diameter with a modified magnetic field configuration was used [13, 14] which allowed a higher degree of the plasma ionization and confinement of plasma near the sputtered target surface. The magnetron was powered using a Dora Power Systems pulse supplier [15] and the power to the magnetron was supplied in full-wave rectified, $165 \mathrm{kHz}$ sinusoidal pulses grouped in the $1.6 \mathrm{kHz}$ unipolar pulse packets [15]. The amplitude of the applied sinusoidal pulses was increased to $1.8 \mathrm{kV}$. The mosaic titanium-niobium target was mounted on the magnetron cooling plate using $1.5 \mathrm{~mm}$ thick and $20 \mathrm{~mm}$ in diameter copper spacer for the sake of a rise of thermal resistivity, which allowed heating of the target close to the melting point. The target to substrate distance was equal to $90 \mathrm{~mm}$ and the substrates temperature was increased to 570 $680 \mathrm{~K}$ during the sputtering process. The low pressure of reactive gas and the magnetron powering conditions resulted in obtaining of amorphous thin films. Detailed description of the preparation method had already been given elsewhere [16]. The thickness of the deposited thin films was $520 \mathrm{~nm}$. The (Ti,Nb)Ox thin films were deposited on Corning 7059 substrates. For the sake of electrical measurements, $\mathrm{NiCrSi}-\mathrm{Ag}$ ohmic contacts were deposited on the thin films surface.

The elemental composition and the surface morphology of the thin films were investigated with the aid of a FESEM FEI Nova NanoSEM 230 scanning electron microscope (SEM). The SEM images were obtained using a low voltage high contrast $\mathrm{vCD}$ detector, which is effective for low voltage $(<3 \mathrm{kV})$ backscattered electron imaging. The elemental composition was measured with the aid of X-ray microanalysis using an EDS EDAX Genesis equipment.

To determine the surface topography properties, AFM measurements were performed by UHV VT AFM/STM Omicron atomic force microscope operating in ultra high vacuum conditions in contact mode.

The type of crystal structure and average crystallites size were determined based on the results of the X-ray diffraction (XRD) measurements using a Siemens D5005 powder diffractometer with $\mathrm{Cu} \mathrm{K} \alpha$ $(\lambda=0.154059 \mathrm{~nm})$ radiation. The crystallites sizes were calculated using Scherrer's equation [17].

X-ray photoelectron spectroscopy (XPS) measurements were performed to determine the oxidation states of each element on the sample surface, with the aid of a Specs Phoibos 100 MCD-5 (5 single channel electron multiplier) hemispherical analyzer using a Specs XR-50 X-ray source with Mg $\mathrm{K} \alpha(1253.6 \mathrm{eV})$ beam. The measurement results were further analysed using CasaXPS software. All spectra were calibrated with respect to the binding energy of adventitious $\mathrm{C} 1 \mathrm{~s}$ peak at $284.8 \mathrm{eV}$.

Optical properties were evaluated on the basis of transmission and reflection measurements. The experimental system was based on an Ocean Optics QE 65000 spectrophotometer with a coupled deuterium-halogen light source. The optical spectra were measured in the wavelength range of 300 to $1000 \mathrm{~nm}$.

The value of resistivity was evaluated after performing several temperature ageing cycles. The thermoelectrical voltage measurements were performed for as-deposited and annealed at $873 \mathrm{~K}$ thin films using a Meratronik V533 multimeter and the temperature was controlled by a Pt100 sensor. Thermoelectrical voltage was investigated in the temperature range of $293 \mathrm{~K}$ to about $613 \mathrm{~K}$. 




(a)

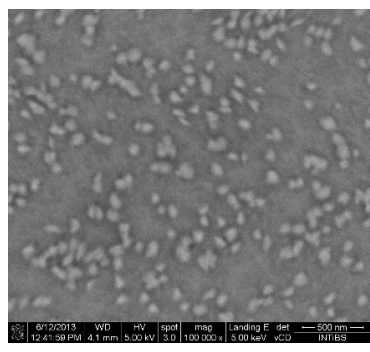

(b)
Fig. 1. SEM images of the surface of the as-deposited $(\mathrm{Ti}, \mathrm{Nb}) \mathrm{Ox}$ thin films at different magnifications: (a) $50000 \times$, (b) $100000 \times$.

\section{Results}

Elemental composition of the prepared thin oxide films was analyzed using energy dispersive $\mathrm{X}$-ray spectroscopy and the estimated niobium concentration was equal to 3.3 at.\% with regard to the titanium and the oxygen contents. In Fig. 1 SEM images of the surface of the investigated thin films are shown. The deposited coatings are crack free, exhibit good adherence to the substrate, no discontinuity of the thin film is observed and the surface morphology is homogeneous. The particles visible in the image (Fig. 1) have different shapes, however their size is in the range of $40-160 \mathrm{~nm}$.

In order to extend the information obtained using the SEM investigations, the AFM measurements of the as-prepared thin films were also performed. AFM measurements confirm the results obtained by the SEM investigations. The images of the film in Fig. 2a and 2b show crack-free surface and densely packed surface composed from the visible grains with repeatable shape. At the surface of the thin films, the grains whose height is of ca. $25-35 \mathrm{~nm}$ are visible. That is also confirmed by the height distribution of the grains and cross-section topography of the surface presented in Fig. 2c and 2d, respectively. The height distribution of the grains contains two visible ranges of ca. $10-15 \mathrm{~nm}$ and $25-35 \mathrm{~nm}$. The calculated RMS surface roughness was found to be equal to $8.98 \mathrm{~nm}$. The cross-section topography of the thin film surface shows that the maximum height of the profile is equal to ca. $35 \mathrm{~nm}$.
The results of XRD measurement of the prepared thin films are presented in Fig. 3. The asdeposited samples were amorphous, while the additional post-process annealing in air at $873 \mathrm{~K}$ caused a change of the structure into the well crystallized $\mathrm{TiO}_{2}$ anatase-rutile mixture. The crystallites sizes (D) were equal to $34.1 \mathrm{~nm}$ and $11.7 \mathrm{~nm}$ for the anatase and rutile, respectively. Such values confirm the nanocrystalline structure of the annealed coatings.

The XPS measurements were performed to determine the chemical states of titanium and niobium on the surface of prepared $(\mathrm{Ti}, \mathrm{Nb}) \mathrm{Ox}$ thin films. In Fig. 4 the Ti2p and Nb3d core level spectra are presented for the as-deposited and the annealed samples.

In case of the as-deposited thin films the position of the Ti2p doublet and the separation energy width equal to $5.8 \mathrm{eV}$ between the Ti2 $\mathrm{p}_{3 / 2}$ and Ti2 $\mathrm{p}_{1 / 2}$ peaks indicates the $\mathrm{Ti}^{4+}$ oxidation state of titanium, which as a result testifies about the formation of $\mathrm{TiO}_{2}$ [20]. However, besides the peaks typical of $\mathrm{Ti}^{4+}$ oxidation state, also a peak related to the oxygen-defficient $\mathrm{Ti}^{3+}$ state was found. That indicates the formation of $\mathrm{Ti}_{2} \mathrm{O}_{3}$ oxide. The ratio of the $\mathrm{TiO}_{2}$ to $\mathrm{Ti}_{2} \mathrm{O}_{3}$ oxides on the surface of the thin film was equal to 96.2 at.\% and 3.8 at.\%, respectively.

The position of the Nb3d doublet and the separation energy width equal to $2.7 \mathrm{eV}$ between the $\mathrm{Nb}_{3} \mathrm{~d}_{5 / 2}$ and $\mathrm{Nb} 3 \mathrm{~d}_{3 / 2}$ peaks indicates the $\mathrm{Nb}^{5+}$ oxidation state. That testifies about the formation of $\mathrm{Nb}_{2} \mathrm{O}_{5}$ on the sample surface [20]. For the asdeposited sample it was also found, that besides niobium at the $\mathrm{Nb}^{5+}$ oxidation state, there were also peaks at $207.9 \mathrm{eV}$ and $204.6 \mathrm{eV}$, which are related to oxygen deficient state of $\mathrm{Nb}^{2+}$. This in turn, indicates on the formation of $\mathrm{NbO}$. The ratio of the $\mathrm{Nb}_{2} \mathrm{O}_{5}$ to $\mathrm{NbO}$ oxides on the surface of the thin film was equal to 91 at.\% and 9 at.\%, respectively.

After the annealing process of the thin films only the Ti2p doublet with the separation energy width equal to $5.7 \mathrm{eV}$ and the Nb3d doublet with the separation energy of $2.8 \mathrm{eV}$ were found on the sample surface. The additional annealing in air led to the full oxidation of titanium and niobium in the 

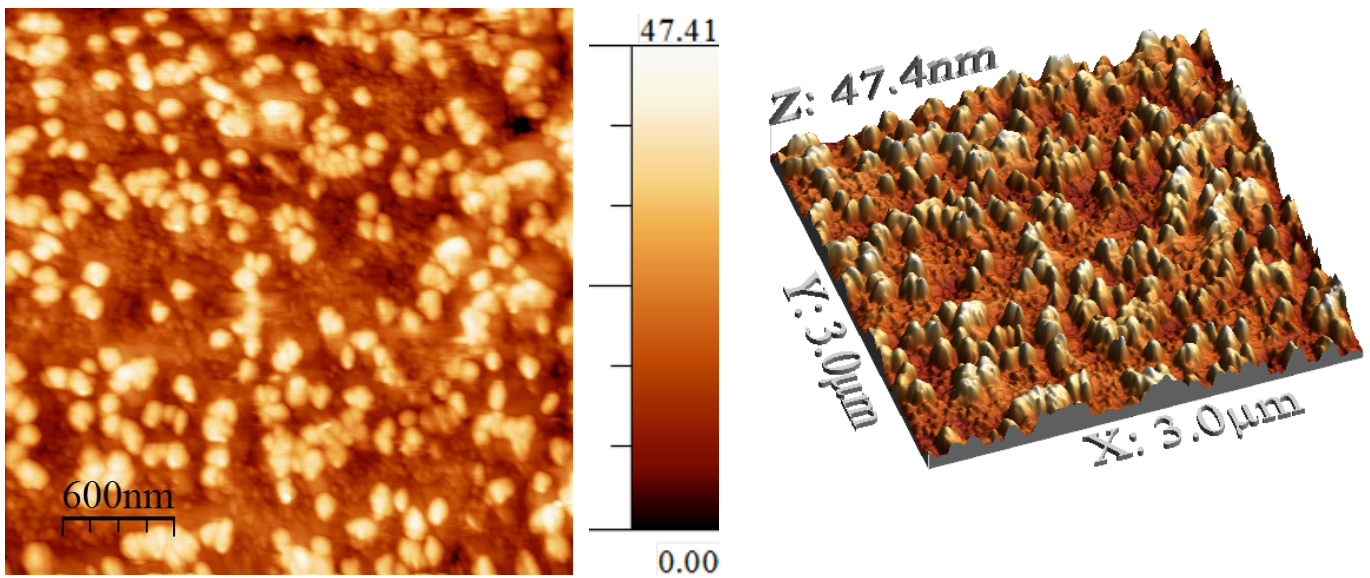

(a)
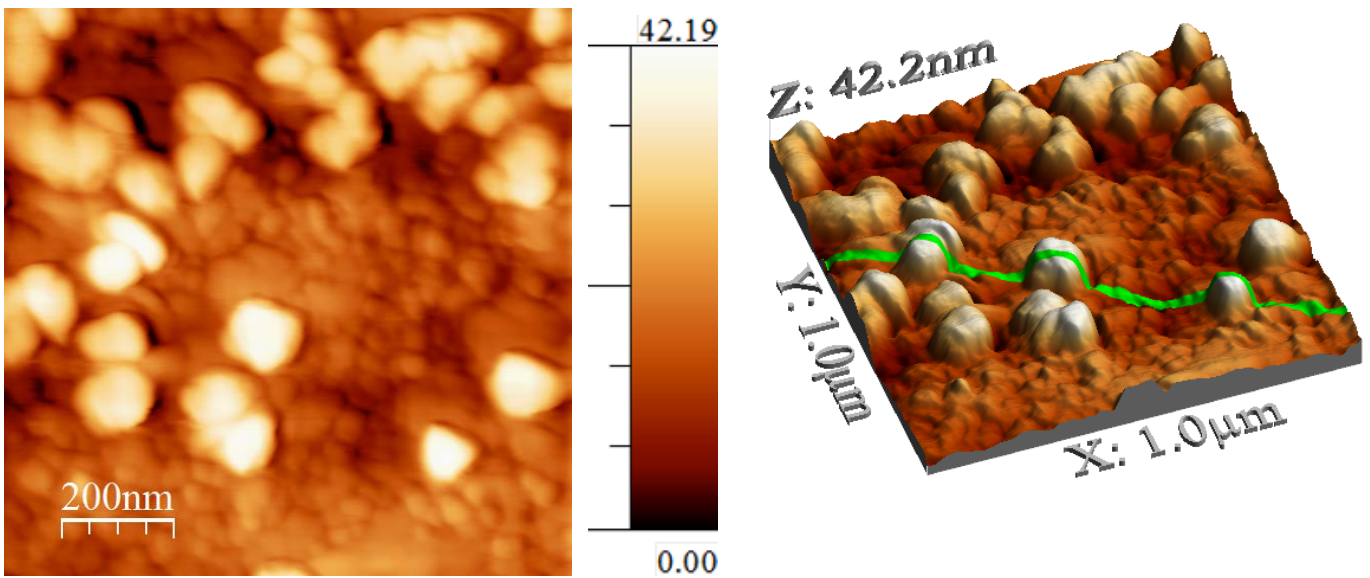

(b)

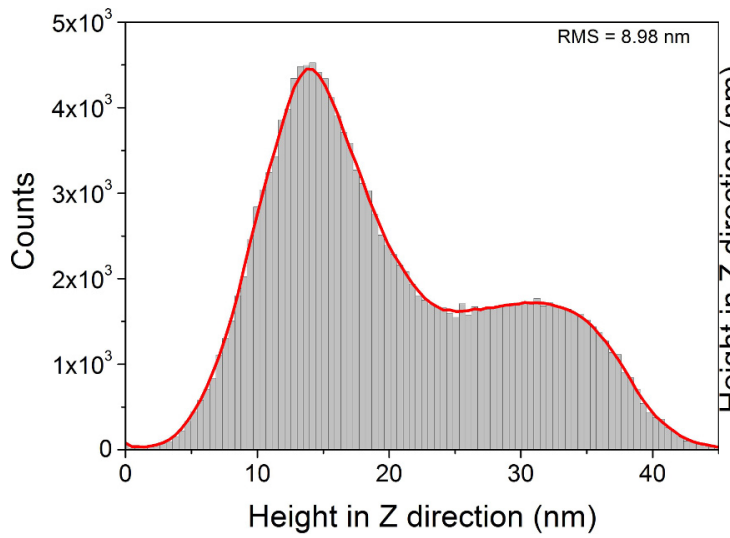

(c)

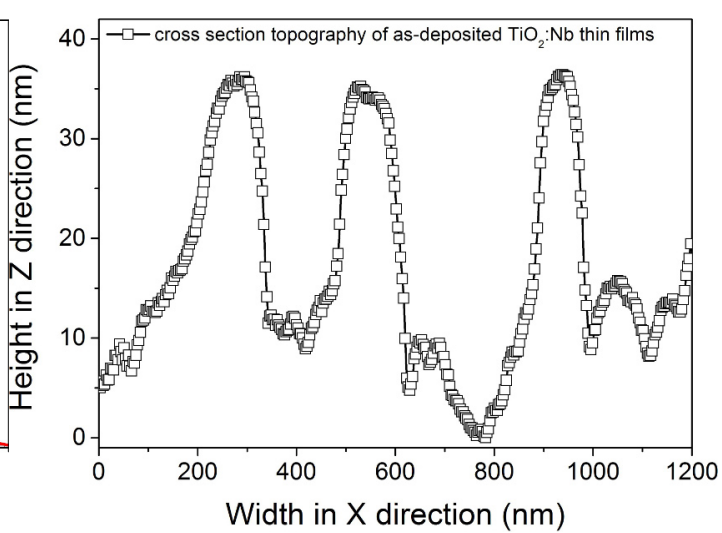

(d)

Fig. 2. AFM measurements results of (Ti,Nb)Ox as-prepared thin films: (a) $3 \times 3 \mu \mathrm{m}$ surface image, (b) $1 \times 1 \mu \mathrm{m}$ surface image, (c) height distribution of grains and (d) cross-section topography of the surface marked with the proper line at the $1 \times 1 \mu \mathrm{m}$ surface image. 


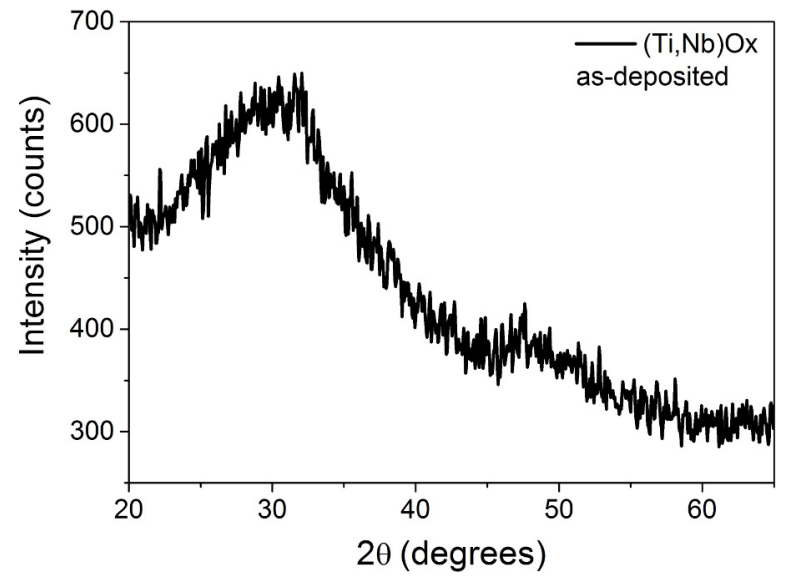

(a)

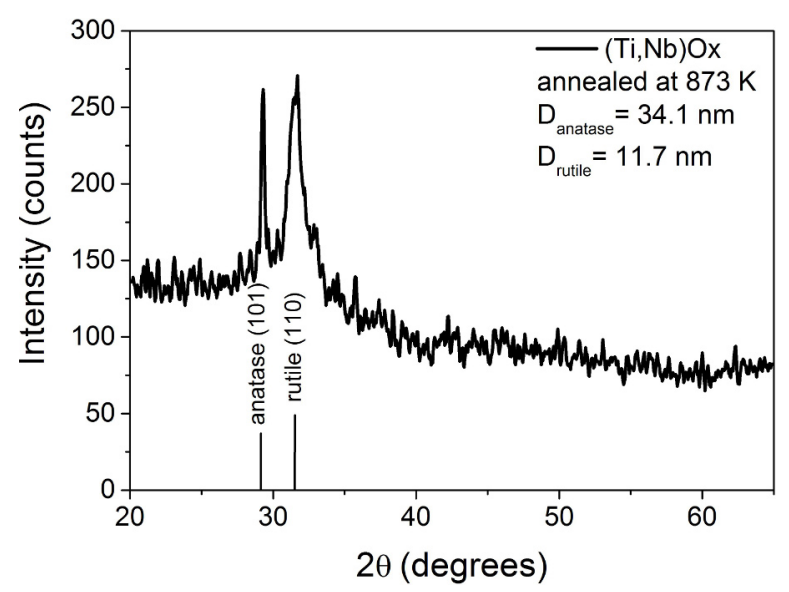

(b)

Fig. 3. XRD patterns of: (a) as-deposited and (b) annealed at $873 \mathrm{~K}(\mathrm{Ti}, \mathrm{Nb}) \mathrm{Ox}$ thin films with marked positions of the anatase and rutile peaks $[18,19]$.

thin films and caused the occurrence of only $\mathrm{Ti}^{4+}$ and $\mathrm{Nb}^{5+}$ oxidation states. Higher oxidation state of niobium ions also caused the generation of titanium vacancies, which in turn allowed one to keep the electrical balance and influence on the thin film resistivity.

The elemental composition of the surface of the thin films was evaluated based on relative sensitivity factors (R.S.F.) for each of the element core levels. The area under each spectrum was evaluated with CasaXPS software. The R.S.F. were equal to 7.9, 8.46 and 2.85 for Ti2p, Nb3d and O1s core levels, respectively. The niobium content calculated using these values was of 4.1 at.\%, which is in a good correlation with the EDS measurement results.

The results of optical properties investigations are shown in Fig. 5. The as-deposited (Ti,Nb)Ox thin films had the transmission of ca. $45 \%$ in the visible light range, while additional annealing caused a significant increase of $10 \%$ in the average. The cut-off wavelength $\left(\lambda_{\text {cut-off }}\right)$ that is the position of the fundamental absorption edge was ca. $346 \mathrm{~nm}$ for the as-deposited sample and the annealing process did not cause any change of this value. While the transmission coefficient increased after the post-process annealing, the reflection coefficient maintained stable, that is neither decrease nor increase was observed. This may testify about the decrease of absorption coefficient after postprocess annealing, which can be the result of the change in oxidation states of titanium and niobium. The fully oxidized $\mathrm{TiO}_{2}$ and $\mathrm{Nb}_{2} \mathrm{O}_{5}$ thin films exhibited higher transmission than the oxygen deficient ones. Additionally, in Fig. 6 the relationship of $\ln \alpha(E)$ for the as-deposited and annealed at $873 \mathrm{~K}(\mathrm{Ti}, \mathrm{Nb}) \mathrm{Ox}$ thin films is presented. The annealing caused the change of the amorphous phase to the rutile-anatase mixed structure. Therefore, the decrease in the Urbach energy after annealing is caused by occurrence of the more ordered crystalline structure as-compared to the amorphous phase. It may also indicate on the decay of the defects in the crystalline structure of annealed thin films. In case of the fine-crystalline structure of the annealed $(\mathrm{Ti}, \mathrm{Nb}) \mathrm{Ox}$ thin films, the still relatively high value of the Urbach energy testifies about diversification of the crystallites size and shape. This may also influence the increase of the transmission coefficient.

In Fig. 7 characteristics of resistivity as a function of the post-process annealing temperature for the $(\mathrm{Ti}, \mathrm{Nb}) \mathrm{Ox}$ thin films are presented. The increase in temperature causes the decrease in resistivity level, which is typical behaviour for semiconductors. The decrease is of one order of magnitude from ca. $1.5 \Omega \mathrm{cm}$ at room temperature to $1.9 \cdot 10^{-1} \Omega \mathrm{cm}$ at $600 \mathrm{~K}$. Several cycles of heating and cooling of the sample were performed. After the $4^{\text {th }}$ cycle only a negligible change of the resistivity value during the change of temperature was 


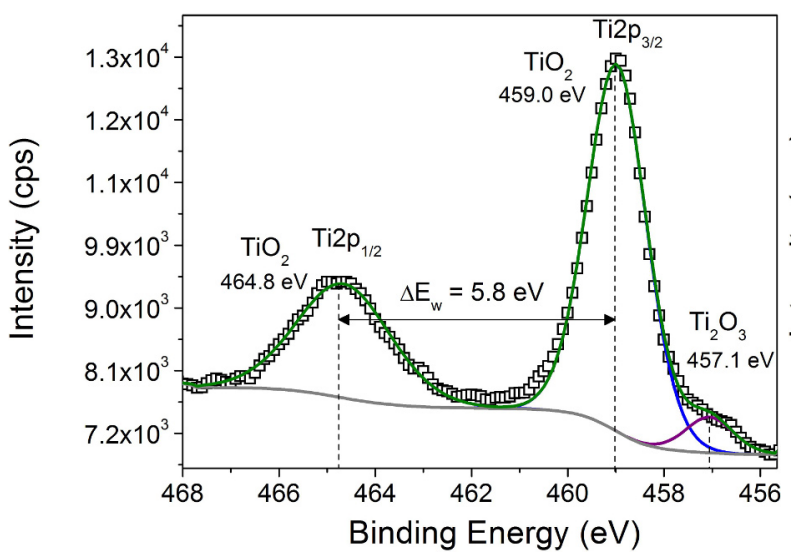

(a)



(c)

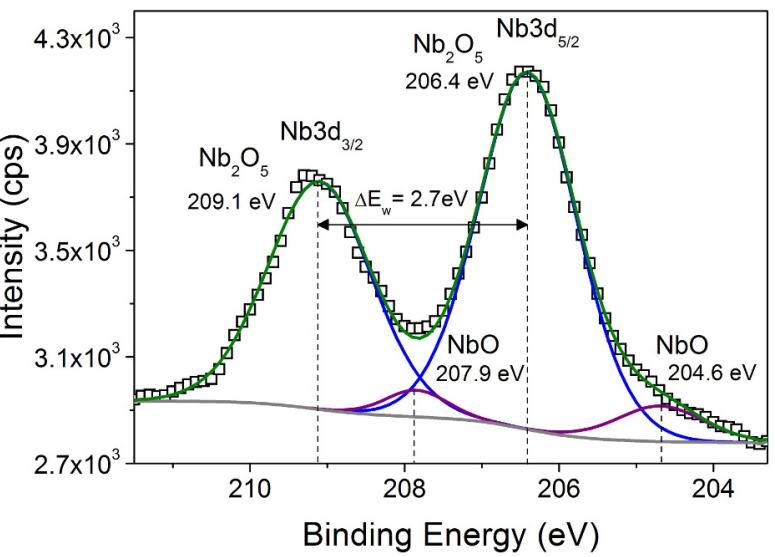

(b)

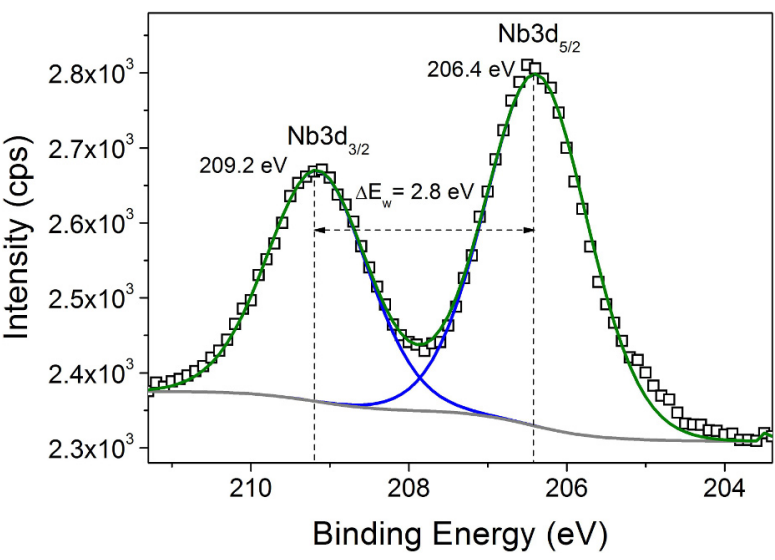

(d)

Fig. 4. XPS results of the (Ti,Nb)Ox thin films: (a) Ti2p and (b) Nb3d core levels of an as-deposited sample, (c) Ti2p and (d) Nb3d core levels of an annealed sample.

recorded. Performing several cycles of heatingcooling of the thin film caused the decrease of resistivity value to $2.3 \cdot 10^{-1} \Omega \mathrm{cm}$ at room temperature and at temperature elevated to $600 \mathrm{~K}$ the resistivity was equal to $6.6 \cdot 10^{-2} \Omega \mathrm{cm}$. Additional postprocess annealing at $873 \mathrm{~K}$ caused the decrease of the resistivity to $4.1 \cdot 10^{-2} \Omega \mathrm{cm}$.

In Fig. 8 characteristics of Seebeck coefficient as a function of temperature for the as-deposited and annealed thin films are presented. The Seebeck coefficient was calculated from the well-known formula, as follows [21]:

$$
S=\lim _{\Delta T \rightarrow 0} \frac{\Delta U}{\Delta T}
$$

where: $S$ is Seebeck coefficient, $\Delta U$ - difference of thermoelectrical voltage, $\Delta T$ - difference of temperature. The sign of the Seebeck coefficient revealed, that the as-deposited $(\mathrm{Ti}, \mathrm{Nb}) \mathrm{Ox}$ thin films exhibited n-type conduction, while the postprocess annealing at $873 \mathrm{~K}$ caused a change of the sign of Seebeck coefficient to the positive. That, in turn, testifies about the p-type conduction of the annealed thin films. Examples known from the literature reports on the thin films of $\mathrm{TiO}_{2}$ doped with $\mathrm{Nb}$ have shown that incorporation of $\mathrm{Nb}$ ions into $\mathrm{TO}_{2}$ lattice results in $\mathrm{n}$ type conductivity [4], and what is more, good electrical conductivity of such magnetron sputtered thin films was obtained only after additional annealing in hydrogen, nitrogen or in a vacuum. To our knowledge, the results presented in the article, reporting the conversion of the type of electrical conduction are unique and so far there have been no reports, which consid- 


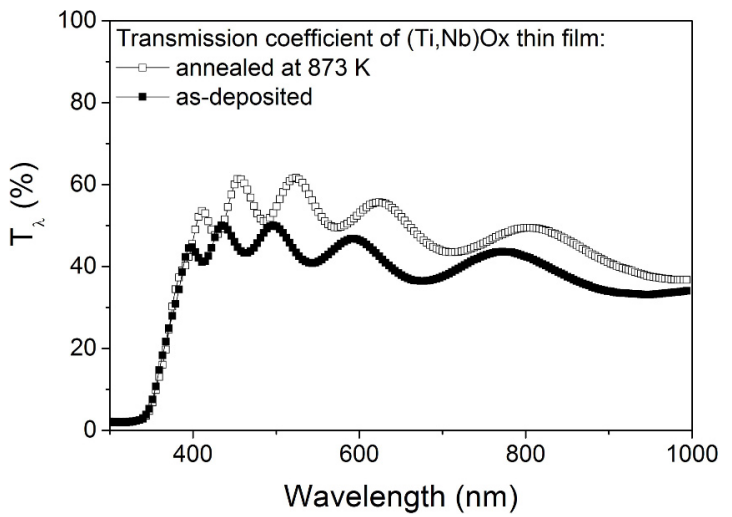

(a)

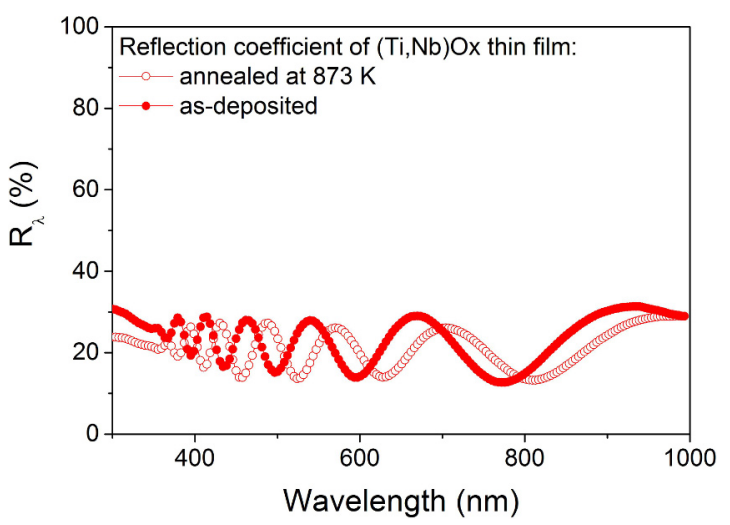

(b)

Fig. 5. The measured spectra of: (a) transmission and (b) reflection of the as-deposited and annealed (Ti,Nb)Ox thin films.

ered such behavior of $(\mathrm{Ti}, \mathrm{Nb}) \mathrm{Ox}$ thin films. Probable factors of the observed conversion are structural changes occurring in the thin film as a result of the annealing. In case of as-deposited samples, from the XPS analysis (Fig. 3) the $\mathrm{Ti}^{3+}, \mathrm{Ti}^{4+}, \mathrm{Nb}^{2+}$ and $\mathrm{Nb}^{5+}$ ions characteristic of the $\mathrm{Ti}_{2} \mathrm{O}_{3}, \mathrm{TiO}_{2}, \mathrm{NbO}$ and $\mathrm{Nb}_{2} \mathrm{O}_{5}$ phases were found. The presence of reduced to +3 and to +2 oxidation states of the titanium and niobium ions, respectively explains the possible source of additional free electrons which disappeared after the annealing. As it is shown in Fig. 3, after the annealing, only crystal phases related to the $\mathrm{TiO}_{2}$ rutile and anatase appeared. What is also worth to emphasize, the value of determined Seebeck coefficient was almost unchanged for both cases of the examined thin films within investigated temperature range. That might indicate the balance between concentrations of the negatively (or posi-

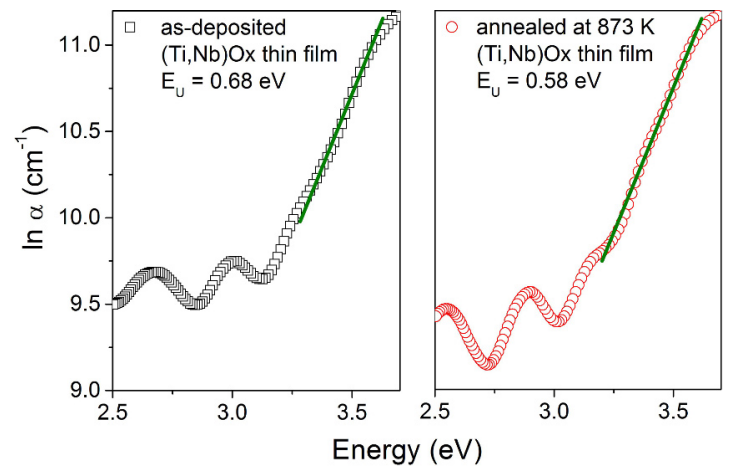

Fig. 6. Relationship of $\ln \alpha(E)$ for the as-deposited and annealed at $873 \mathrm{~K}(\mathrm{Ti}, \mathrm{Nb}) \mathrm{Ox}$ thin films.



Fig. 7. Resistivity of the (Ti,Nb)Ox thin films in a function of temperature.



Fig. 8. Seebeck coefficient characteristics versus temperature for the as-deposited and annealed (Ti,Nb)Ox thin films. 
tively) charged extrinsic and thermally activated intrinsic electrical carriers. The source of the intrinsic electrical carriers could be the structure, which is connected with the presence of electrically charged surface of nanocrystalls, grain boundaries, oxygen deficiencies, etc., which may act as traps for electrical charge carriers or may release additional electrons or holes upon thermal activation.

\section{Conclusions}

The (Ti,Nb)Ox thin films were deposited using the high energy magnetron sputtering. The niobium concentration in the thin films was estimated as 3.3 at. \%. The as-deposited samples were amorphous, while additional annealing caused the structure transformation to the two-phase component system of the $\mathrm{TiO}_{2}$ anatase-rutile mixture with crystallites of $34.1 \mathrm{~nm}$ and $11.7 \mathrm{~nm}$, respectively. The surfaces of the as-deposited thin films were composed of the $\mathrm{TiO}_{2}, \mathrm{Nb}_{2} \mathrm{O}_{5}$ and oxygen deficient $\mathrm{Ti}_{2} \mathrm{O}_{3}$ and $\mathrm{NbO}$, while the annealed coatings were composed only from the $\mathrm{TiO}_{2}$ and $\mathrm{Nb}_{2} \mathrm{O}_{5}$ oxides.

The average transmission was about $45 \%$, however additional annealing increased it to ca. $55 \%$. Incorporation of niobium caused a significant decrease of the resistivity value. The undoped $\mathrm{TiO}_{2}$ is a dielectric material with resistivity of ca. $10^{8} \Omega \mathrm{cm}$, while incorporation of only 3.3 at.\% of niobium caused its decrease to ca. $1.5 \Omega \mathrm{cm}$. Additional postprocess annealing at $600 \mathrm{~K}$ caused further decrease of the resistivity to $2.2 \cdot 10^{-1} \Omega \mathrm{cm}$. Also, what is worth to emphasize, the as-deposited thin film were the n-type conductors, while the post-process annealing changed this behaviour to the p-type conduction.

\section{Acknowledgements}

Authors would like to thank prof. Leszek Kepinski from Institute of Low Temperature and Structure Research for performing the SEM and EDS studies.

This work was financed from the sources granted by the NCN in the years $2013-2015$ and $2014-2017$ as a research projects No.: DEC-2012/05/N/ST7/00173, DEC2013/08/T/ST7/00131 and DEC-2013/09/B/ST7/01592.

\section{References}

[1] Domaradzki J., J. Non-Cryst. Solids, 352 (2006), 2328.
[2] Domaradzki J., Thin Solid Films, 497 (2006), 243.

[3] Domaradzki J., Borkowska A., KaczmareK D., Prociów E., Opt. Appl., 37 (2007), 133.

[4] Furubayashi Y., Hitosugi T., Yamamoto Y., Hirose Y., Kinoda G., Inaba K., Shimada T., Hasegawa T., Appl. Phys. Lett., 86 (2005), 252101-1.

[5] Furubayashi Y., Hitosug T., Yamamoto Y., HiRose Y., Kinoda G., InABA K., Shimada T., HASEgawA T., Thin Solid Films, 496 (2006), 157.

[6] Prociów E., Domaradzki J., Kaczmarek D., BERLICKI T., BorkowsKa A., SierADZKA K., Studies of electrical and optical properties of $\mathrm{TiO}_{2}:(\mathrm{Co}, \mathrm{Pd})$ thin films prepared by LP HTRS method, XXXI IMAPS Poland Chapter Conf., Rzeszów - Krasiczyn, September 2007, 167.

[7] Anukunprasert T., Saiwana C., Traversa E., Sci. Technol. Adv. Mat., 6 (2005), 359.

[8] Guidi V., Martinelli G., Schiffrer G., Vomiero A., Scian C., Della Mea G., Comini E., Ferroni M., Sberveglieri G., Sensor. Actuat. B-Chem., 108 (2005), 21.

[9] Lin H., Kozuka H., Yoko T., J. Sol-Gel Sci. Techn., 19 (2000), 529.

[10] NATSUHARA H., Matsumoto K, Yoshida N., Itoh T., Nonomura S., Fukawa M., Sato K., Sol. Energ. Mat. Sol. C., 90 (2006), 2867.

[11] Pociow E.L., Domaradzki J., Kaczmarek D., Berlicki T., Polish patent No. P382163, 2007.

[12] Domaradzki J., Kaczmarek D., Prociow E., RadZimski Z., Acta Phys. Pol. A, 120 (1), 2011, 49.

[13] Posadowski W.M., Polish patent No. 153969, 1991.

[14] Posadowski W.M., Thin Solid Films, 343 - 344 (1999), 85.

[15] Dora J., Polish Patent No. 313150, 1996.

[16] Kaczmarek D., Prociów E., Domaradzki J., Borkowska A., MielcareK W., Wojcieszak D., Mater. Sci.-Poland, 26 (1) (2008), 113.

[17] Klug H.P., Alexander L.E., IN: Klug H.P., AleXANDER L.E. (EDS.), X-ray Diffraction Procedures for Polycrystalline and Amorphous Materials, $2^{\text {nd }}$ edition, John Wiley and Sons, New York, 1974.

[18] Powder Diffraction File, Joint Committee on Powder Diffraction Standards, Philadelphia, PA: ASTM; 1967 Card 21-1272.

[19] Powder Diffraction File. Joint Committee on Powder Diffraction Standards, Philadelphia, PA: ASTM; 1967 Card 21-1276.

[20] Moulder J., Stickle W., Sobol P., Bomben K., Handbook of X-ray Photoelectron Spectroscopy, Physical Electronics Inc., USA, ISBN 0-9648124-1-X, 1995.

[21] Goto T., Li J.H., Hirai T., Maeda Y., Int. J. Thermophys., 18 (2) (1997), 569. 